Article

\title{
Hierarchical Core/Shell Structured Ag@Ni(OH) Nanospheres as Binder-Free Electrodes for High Performance Supercapacitors
}

\author{
Sa Lv*(D), Xuefeng Chu, Fan Yang, Huan Wang ${ }^{\mathbb{D}}$, Jia Yang, Yaodan Chi and Xiaotian Yang * \\ Jilin Provincial Key Laboratory of Architectural Electricity \& Comprehensive Energy Saving, School of Electrical \\ Engineering and Computer, Jilin Jianzhu University, Changchun 130118, China; stone2009@126.com (X.C.); \\ ctpnxn@163.com (F.Y.); whuan@ciac.ac.cn (H.W.); yangjia@jlju.edu.cn (J.Y.); chiyaodan@jlju.edu.cn (Y.C.) \\ * Correspondence: 1vsa82@163.com (S.L.); hanyxt@163.com (X.Y.); Tel.: +86-0431-8456-6181 (S.L.)
}

Received: 27 January 2019; Accepted: 21 February 2019; Published: 24 February 2019

\begin{abstract}
Hierarchical Ag@Ni(OH $)_{2}$ nanospheres were achieved directly on copper foam substrate through a convenient two-step process. Ag nanoflowers were formed on copper substrate by galvanic replacement technology between $\mathrm{AgNO}_{3}$ and copper foam followed by electrodeposition of a layer of $\mathrm{Ni}(\mathrm{OH})_{2}$. Ag nanostructures as cores not only dominated the final morphology of the composites, but also improved the electrical conductivity, increased the specific surface area of the active electrode material, and even directly participated in the electrochemical reactions. The resulted $\mathrm{Ag} @ \mathrm{Ni}(\mathrm{OH})_{2}$ nanospheres could be directly used as high-performance binder-free electrodes and exhibited enhanced electrochemical performance with a high specific capacitance of $1.864 \mathrm{~F} \mathrm{~cm}^{-2}$ and long cycling lifespans of $90.43 \%$ capacity retaining after 3000 cycles.
\end{abstract}

Keywords: electrodeposition; $\mathrm{Ag} @ \mathrm{Ni}(\mathrm{OH})_{2}$ nanospheres; electrode material; supercapacitor

\section{Introduction}

Supercapacitors, as one of the most efficient energy storage and conversion devices have attracted ever-increasing interest due to their fast charging-discharging rate, remarkable power density and long cycling lifespans [1]. It is generally believed that the electrochemical performances of supercapacitor depend mainly on the electrode materials [2]. Among these candidates, pseudocapacitive materials of transition metal hydroxides/oxides, including $\mathrm{Ni}(\mathrm{OH})_{2} / \mathrm{NiO}$ [3], $\mathrm{Co}_{3} \mathrm{O}_{4}$ [4] and $\mathrm{MnO}_{2}$ [5] have attracted considerable attention because of their reversible redox behavior, reasonable cost and environmentally friendly characteristics [6,7]. $\mathrm{Ni}(\mathrm{OH})_{2}$ is considered as the most competitive candidate owing to its high chemical stability, natural abundance of nickel compounds and high theoretical specific capacity. A large number of in-depth explorations have been performed on optimizing the performance of $\mathrm{Ni}(\mathrm{OH})_{2}$. But the relatively low conductivity and active surface areas often limit the effective utilization of electrode materials, and lead to the reduction of energy and power density. To address these problems, three strategies have been conceived: (1) Constructing hybrid materials by adding components or elements with high conductivity, such as graphene, $\mathrm{Ag}, \mathrm{Au}$ and $\mathrm{Cu}$; (2) Designing various hierarchical structures, forming porous structure or reducing particle size in order to increase the specific surface area of the active materials; (3) Adopting chemically stable conductive substrates with proper surface modification, such as copper foam [8], stainless steel mesh [9], cotton textile [10] and paper [11]. For example, Gong and coworkers [12] fabricated $\mathrm{Ni}(\mathrm{OH})_{2}-\mathrm{Cu}$ hybrid electrode by hydrothermal method, which exhibited an ultrahigh areal capacitance of $8.66 \mathrm{~F} \mathrm{~cm}^{-2}$ at $1 \mathrm{~mA} \mathrm{~cm}{ }^{-2}$. The prominent enhancement is attributed to the highly conductive path provided by the metallic $\mathrm{Cu}$ layer, which facilitates charge transport and benefits fast redox 
reaction. Jeyasubramanian et al. [13] reported the growth of $\mathrm{MnO}_{2}$ nanostructures on hierarchical $\mathrm{Cu}$ nanoleaves via a two-step electrodeposition, which demonstrated a high specific capacitance of $486 \mathrm{~F} \mathrm{~g}^{-1}$ at $1 \mathrm{~mA} \mathrm{~cm}{ }^{-2}$. Shin and coworkers [14] described the decoration of $\mathrm{Co}_{3} \mathrm{O}_{4}$ by $\mathrm{Ag}$ nanoparticles using chemical immersion method, and the composite electrode achieved a superior specific capacitance of $958 \mathrm{~F} \mathrm{~g}^{-1}$. These works revealed that the reasonable design and construction of metal hydroxides/oxides-based materials with conductive reinforcement is an effective method to enhance the electrochemical performances of the hybrid electrodes.

Previous published papers have confirmed the use of $\mathrm{Ag}$ as an enhancement component owing to its stability, high electrical conductivity and electrochemical activity. Therefore, it is reasonable to believe that $\mathrm{Ag} / \mathrm{Ni}(\mathrm{OH})_{2}$ composite electrode will have excellent electrochemical properties. The existing technologies to achieve $\mathrm{Ag} / \mathrm{Ni}(\mathrm{OH})_{2}$ composite usually involve two steps. The initial $\mathrm{Ag}$ nanostructures could be obtained by various methods, such as electrodeposition and hydrothermal method [15]. After that, the metal hydroxides/oxides were grown on the Ag electrode surface via hydrothermal or electrodeposition $[16,17]$. The hierarchical structure is helpful to exert the synergistic effect between each component and enhances the overall electrochemical properties thereby. However, the resulting samples in a powdered state must be pressed onto the substrates to fabricate electrodes with a binder and acetylene black. The incorporation of ancillary materials often results in the inadequate contact at the interfaces between electrode materials and substrate, which were inhibiting the performance of the supercapacitors. Therefore, it is urgent to explore a high-efficiency strategy for realizing in-situ construction of composite materials and using directly as high performance binder-free electrodes.

In view of the above analysis, hierarchical $\mathrm{Ag} @ \mathrm{Ni}(\mathrm{OH})_{2}$ nanospheres have been constructed on copper substrate herein through a convenient two-step process. Galvanic replacement reaction between $\mathrm{AgNO}_{3}$ and copper foam was exploited to generate silver nanoflowers directly on copper foam substrate. The $\mathrm{Ni}(\mathrm{OH})_{2}$ layer was constantly loaded on silver nanoflowers surface by electrodeposition. The resulting $\mathrm{Ag} @ \mathrm{Ni}(\mathrm{OH})_{2}$ samples as binder-free electrodes exhibited enhanced electrochemical performances, which was mainly attributed to the synthesis strategy and the effective utilization of $\mathrm{Ag}$ as backbone. The Ag element could improve the electrical conductivity and increase the specific surface area of the active electrode material.

\section{Materials and Methods}

\subsection{Materials}

Copper substrate was carefully cleaned by toluene, acetone, ethanol and deionized water, and then immersed into $\mathrm{HCl}$ aqueous solution $(1 \mathrm{M})$ before use in order to remove surface oxides. Silver nitrate $\left(\mathrm{AgNO}_{3}, 99.8 \%\right)$, nickel nitrate $\left(\mathrm{Ni}\left(\mathrm{NO}_{3}\right)_{2} \cdot 6 \mathrm{H}_{2} \mathrm{O}, 99 \%\right)$ and $\mathrm{NaOH}$ were used in this report.

\subsection{Synthesis of Hierarchical Ag@Ni(OH) 2 Electrode}

In a typical procedure, the precleaned copper foam was suspended and immersed into an $\mathrm{AgNO}_{3}$ aqueous solution $(0.01 \mathrm{M})$ for $10 \mathrm{~min}$. After that, the copper foam with gray silver precipitates was rinsed with ethanol and deionized water, and then, a freshly prepared $\mathrm{Ni}\left(\mathrm{NO}_{3}\right)_{2} \cdot 6 \mathrm{H}_{2} \mathrm{O}$ aqueous solution $(0.05 \mathrm{M})$ was used to deposit $\mathrm{Ni}(\mathrm{OH})_{2}$ onto the $\mathrm{Ag}$ core for $300 \mathrm{~s}$. In the three-electrode system, the $\mathrm{Ag}$ /copper foam acts as working electrode, a platinum foil acts as counter electrode, and saturated calomel electrode (SCE) acts as reference electrode. The potentiostatic deposition was performed about $300 \mathrm{~s}$ at $-1.0 \mathrm{~V}$ vs. SCE. At last, the resulting copper foam was rinsed with ethanol and deionized water.

\subsection{Materials Characterization}

The products were characterized by X-ray diffraction (XRD) using Cu K $\alpha$ radiation $(\lambda=1.5406 \AA)$ and field-emission scanning electron microscopy (FE-SEM JEOL JSM-7610F, Japan) equipped with 
an energy dispersive X-ray spectrometer (EDS). The X-ray photoelectron spectroscopy spectra (XPS) measurement was performed on an ESCALAB 250Xi (ThermoFisher Scientific Co., Ltd, USA) with Al $\mathrm{K} \alpha$ as the $\mathrm{X}$-ray source.

\subsection{Electrochemical Measurements}

The electrochemical performance was evaluated on an electrochemical workstation (Shanghai Chenhua Instrument CHI 660D), including cyclic voltammetry (CV) and galvanostatic charge-discharge test (GCD). The three-electrode system consists of the obtained $\mathrm{Ag} @ \mathrm{Ni}(\mathrm{OH})_{2}$ composite, a platinum foil and $\mathrm{Hg} / \mathrm{HgO}(0.098 \mathrm{~V})$. They serve as working electrodes, counter electrode and reference electrode, respectively. The electrolyte was a 5-M NaOH solution. The cycling performance has been assessed involving the Neware testing system.

\section{Results}

The construction process of $\mathrm{Ag} @ \mathrm{Ni}(\mathrm{OH})_{2}$ electrode is shown in Scheme 1. Firstly, a convenient galvanic replacement reaction route is designed based on the following equation: $\mathrm{Cu}(\mathrm{s})+2 \mathrm{Ag}^{+}$ $(\mathrm{aq}) \rightarrow 2 \mathrm{Ag}(\mathrm{s})+\mathrm{Cu}^{2+}(\mathrm{aq})$ [18]. Ag nanoflowers stuck to copper substrate are obtained by immersing of the copper substrate into $\mathrm{AgNO}_{3}$ solution $(0.01 \mathrm{M})$ for $10 \mathrm{~min}$. In this process, copper foam acts as both reducing agent and substrate. After that, the electrochemical deposition process was performed in a three-electrode system using the $\mathrm{Ni}\left(\mathrm{NO}_{3}\right)_{2} \cdot 6 \mathrm{H}_{2} \mathrm{O}$ aqueous solution as electrolyte. The $\mathrm{OH}^{-}$ generated by electrolytic reaction at the $\mathrm{Ag}$ electrode surface causes constant $\mathrm{Ni}(\mathrm{OH})_{2}$ deposited, and thus hierarchical $\mathrm{Ag} @ \mathrm{Ni}(\mathrm{OH})_{2}$ nanospheres are formed as described by the following equations [19]:

$$
\begin{gathered}
\mathrm{NO}_{3}^{-}+\mathrm{H}_{2} \mathrm{O}+2 \mathrm{e}^{-} \rightarrow \mathrm{NO}_{2}^{-}+2 \mathrm{OH}^{-} \\
\mathrm{Ni}^{2+}+2 \mathrm{OH}^{-} \rightarrow \mathrm{Ni}(\mathrm{OH})_{2} \downarrow
\end{gathered}
$$

Figure 1a shows the original FE-SEM image of copper foam substrate with 3D net structure. An overview FE-SEM image of the products obtained through galvanic replacement reaction between $\mathrm{AgNO}_{3}$ and copper foam is shown in Figure 1b, where the uniform and dense Ag nanostructure is observed on the copper substrate. The magnified image in Figure 1c shows that the products are nanoflowers, which are made up of a number of nanosheets with thickness of about $20 \mathrm{~nm}$ and rough surface (Figure 1d).

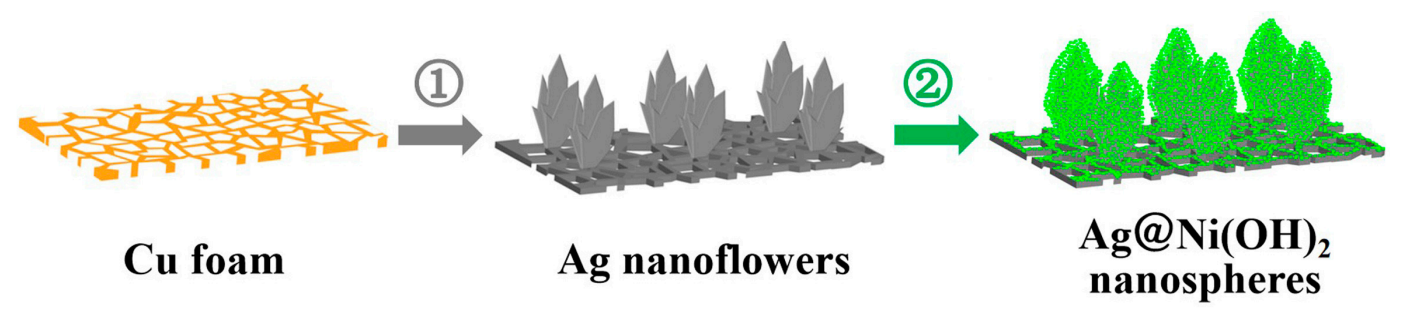

\section{(1) galvanic replacement reaction; (2) electrodeposition}

Scheme 1. The illustration of the in-situ construction process of core/shell structured $\mathrm{Ag} @ \mathrm{Ni}(\mathrm{OH})_{2}$ electrode.

The subsequent electrochemical deposition allows the coating of uniform $\mathrm{Ni}(\mathrm{OH})_{2}$ layer on the surface of Ag nanoflowers. As can be realized from Figure 2a, Ag nanoflowers are covered tightly with a dense layer of $\mathrm{Ni}(\mathrm{OH})_{2}$ when the deposition time is only $30 \mathrm{~s}$. The original shape of the $\mathrm{Ag}$ nanoflowers constructed by numbers of nanosheets is clearly visible. The corresponding EDS element mapping images and EDS spectrum (in inset of Figure 2a) confirm the existence of $\mathrm{Cu}, \mathrm{Ag}, \mathrm{Ni}$ and $\mathrm{O}$ elements. Further observation of the enlarged image in Figure $2 \mathrm{~b}$ confirms that in addition to the tightly wrapped a layer of $\mathrm{Ni}(\mathrm{OH})_{2}$ on the surface of the $\mathrm{Ag}$ nanosheets, a large number of $\mathrm{Ni}(\mathrm{OH})_{2}$ 
nanospheres with regular shapes are deposited on the surface with a mean diameter of about $260 \mathrm{~nm}$ (Figure 2c).
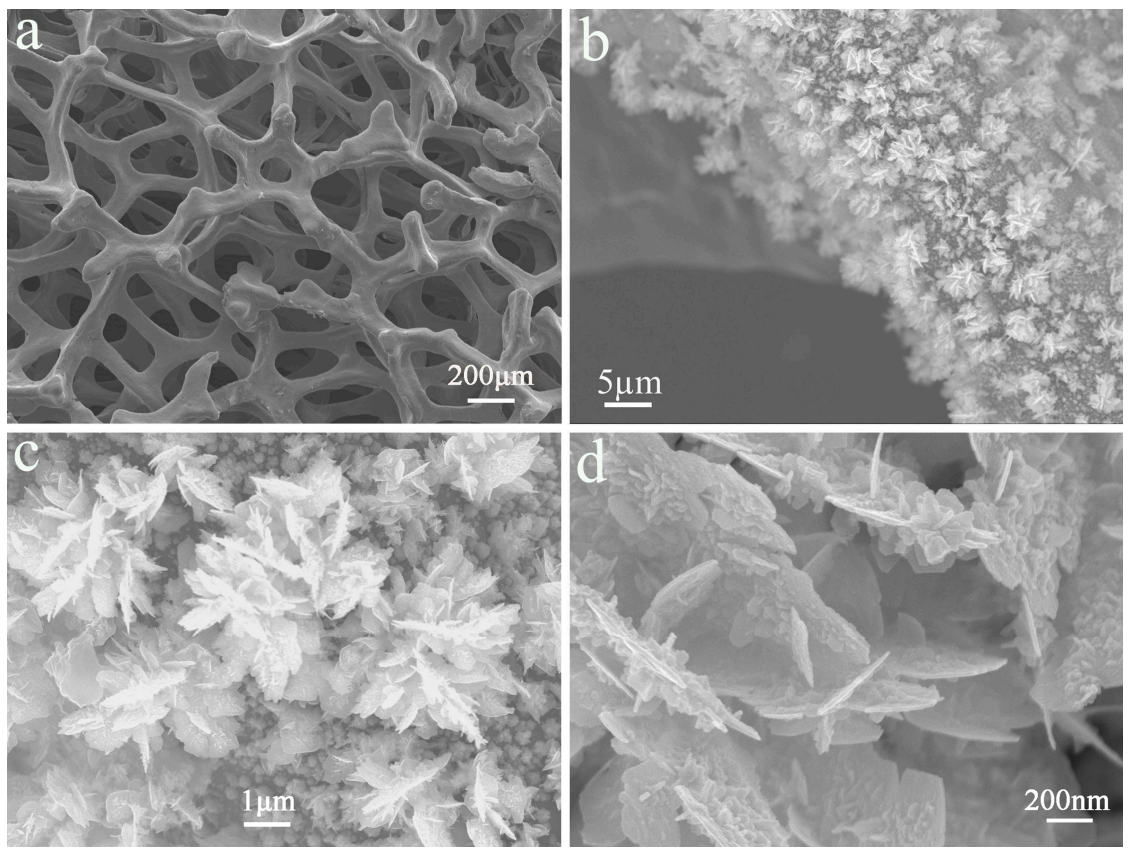

Figure 1. FE-SEM images: (a) pristine nickel foam; (b-d) Ag nanoflowers at different magnifications.
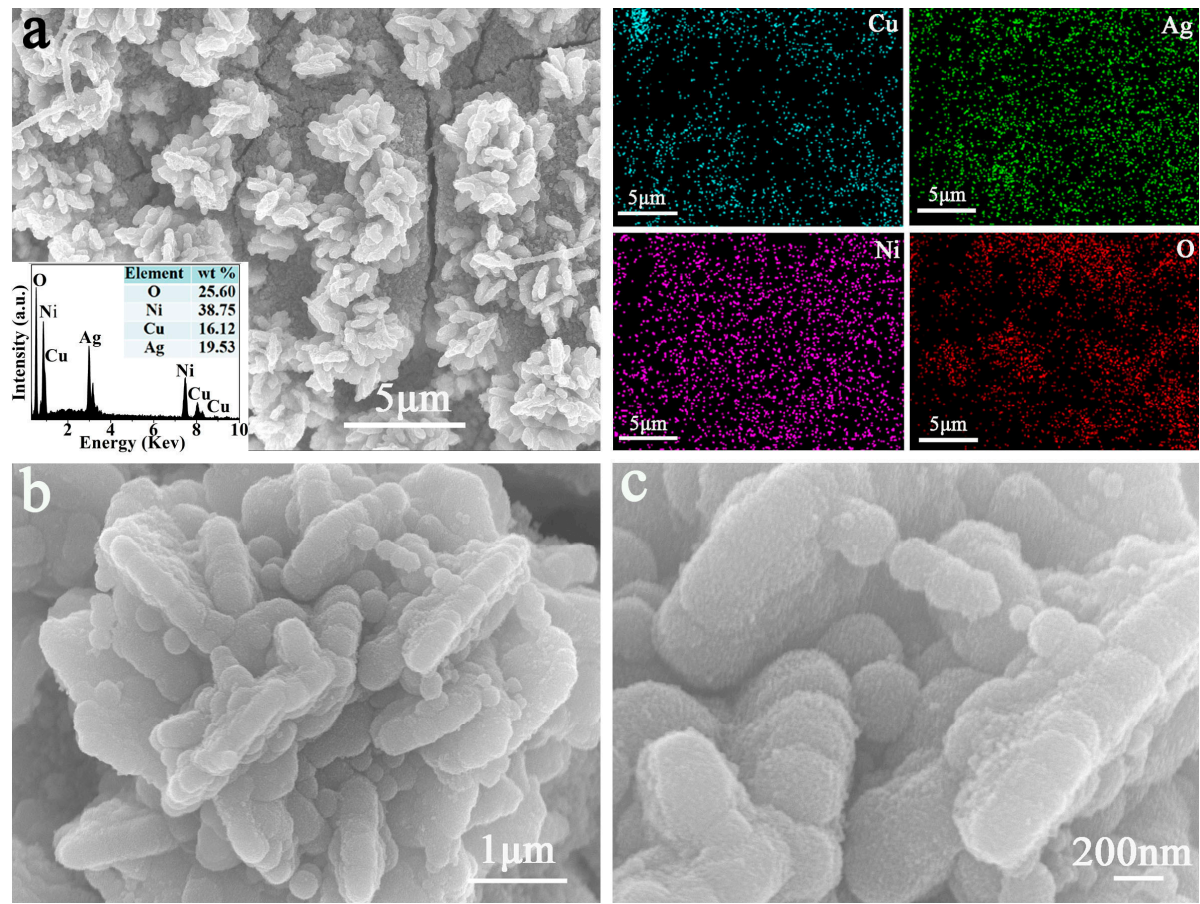

Figure 2. FE-SEM images of the $\mathrm{Ag} @ \mathrm{Ni}(\mathrm{OH})_{2}$ composite with $30 \mathrm{~s}$ the deposition time of $\mathrm{Ni}(\mathrm{OH})_{2}$ : (a) Low magnification image and the EDS element mapping, inset is the EDS spectrum; (b-c) high magnification images.

When the deposition time is up to $300 \mathrm{~s}$, as shown in Figure $3 \mathrm{a}, \mathrm{Ni}(\mathrm{OH})_{2}$ nanospheres with a diameter of about $650 \mathrm{~nm}$ are found to be packed closely with each other, and the corresponding EDS element mapping images reveal the coexistence of $\mathrm{Cu}, \mathrm{Ag}$, $\mathrm{Ni}$ and $\mathrm{O}$ elements. Figure $3 \mathrm{~b}, \mathrm{c}$ present the magnified images of $\mathrm{Ni}(\mathrm{OH})_{2}$ nanospheres. The $\mathrm{Ni}(\mathrm{OH})_{2}$ nanospheres are composed of a large 
number of smaller nanoparticles with diameter of about $10 \mathrm{~nm}$, which are interconnected with each other to form a worm-like structure.
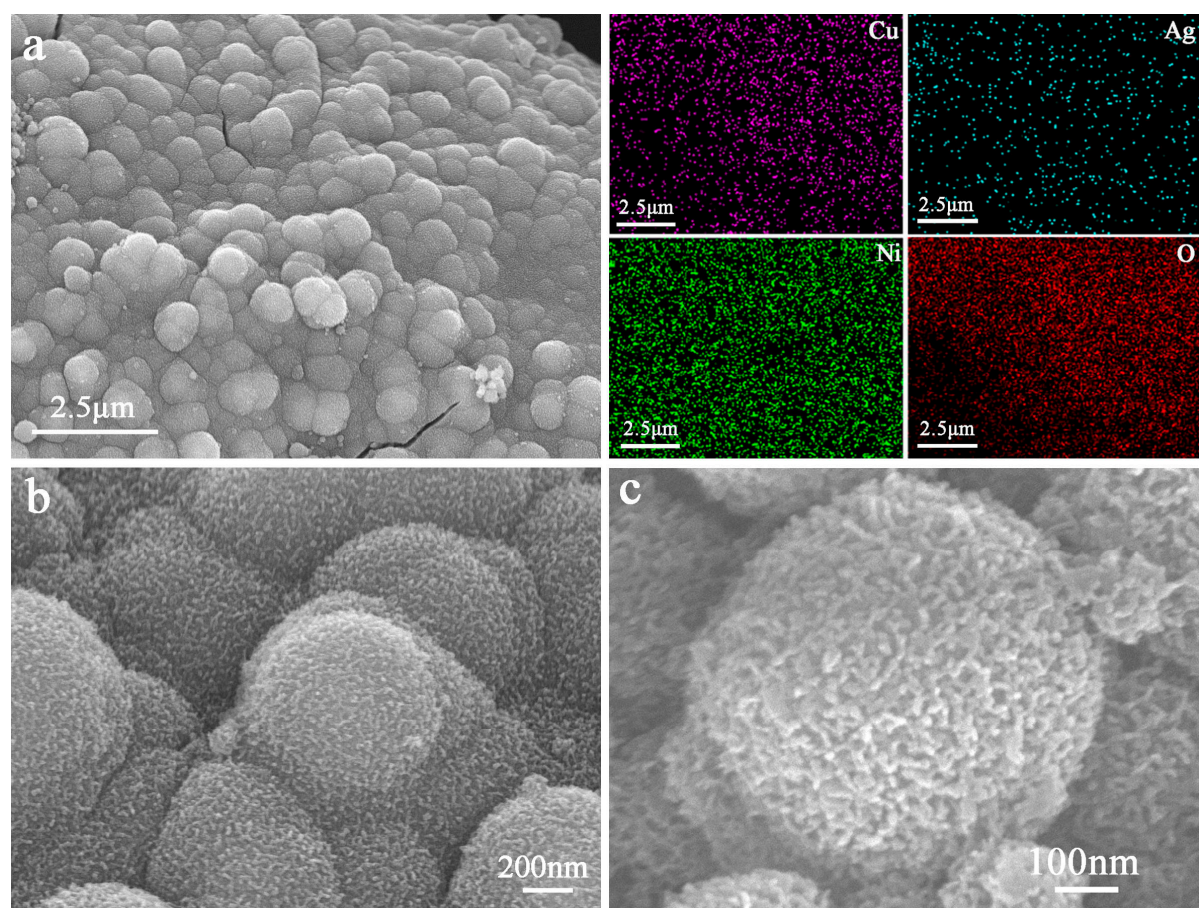

Figure 3. FE-SEM images of the $\mathrm{Ag} @ \mathrm{Ni}(\mathrm{OH})_{2}$ composite with $300 \mathrm{~s}$ the deposition time of $\mathrm{Ni}(\mathrm{OH})_{2}$ :

(a) Low magnification image and the EDS element mapping; $(\mathbf{b}, \mathbf{c})$ high magnification images.

Figure 4 a presents the XRD patterns of Ag nanoflowers and $\mathrm{Ag} @ \mathrm{Ni}(\mathrm{OH})_{2}$ composite on copper foam. Three characteristic peaks labeled with asterisks belong to the copper substrate (JCPDS card no. 01-1241), the as-synthesized Ag nanoflowers display crystalline peaks at diffraction angle of about $38.12^{\circ}, 44.28^{\circ}$ and $77.48^{\circ}$ corresponding to (111), (200) and (311) crystalline plane, respectively, in good agreement with the face-centered cubic (fcc) Ag (JCPDS card no. 04-0783). The Ag@Ni(OH) 2 composite exhibits (100), (101) and (111) crystalline peaks at $33.52^{\circ}, 38.64^{\circ}$ and $62.66^{\circ}$, indicating the $\beta$ phase of $\mathrm{Ni}(\mathrm{OH})_{2}$ ( JCPDS card no. 14-0117). XPS was carried out to further verify the deposition of $\mathrm{Ni}(\mathrm{OH})_{2}$ layer on the surface of Ag nanoflowers. The survey spectrum in Figure $4 \mathrm{~b}$ confirms the presence of $\mathrm{C}, \mathrm{O}, \mathrm{Ni}$ and Ag elements, agreeing with the EDS result. The spectrum of $\mathrm{Ag} 3 \mathrm{~d}$ shows two peaks at 368.2 and $374.4 \mathrm{eV}$, as shown in Figure $4 \mathrm{c}$, which originated from $\mathrm{Ag} 3 \mathrm{~d}_{5 / 2}$ and $\mathrm{Ag} 3 \mathrm{~d}_{3 / 2}$, respectively. Figure 4d presents the Ni LMM (L-inner level-M-inner level-M-inner level electron transition) Auger spectrum with the Auger peak of $841.8 \mathrm{eV}$, the peak shape is in good agreement with the literature [20]. The spectrum of $\mathrm{Ni} 2 \mathrm{p}$ shows two major peaks in Figure 4e, the binding energies at 856 and $873.7 \mathrm{eV}$ are ascribed to $\mathrm{Ni} 2 \mathrm{p}_{3 / 2}$ and $\mathrm{Ni} 2 \mathrm{p}_{1 / 2}$, respectively. So the spin-orbit coupling energy separation is $17.7 \mathrm{eV}$, and the Auger parameter of $\mathrm{Ni}(\mathrm{OH})_{2}$ is $1698 \mathrm{eV}[16,20,21]$. In addition, two satellite peaks at 861.7 and $880 \mathrm{eV}$ correspond to the binding energies of $\mathrm{Ni} 2 \mathrm{p}_{3 / 2}$ and $\mathrm{Ni} 2 \mathrm{p}_{1 / 2}$, respectively. The peak of $\mathrm{O} 1 \mathrm{~s}$ spectrum located at around $531 \mathrm{eV}$ can be attributed to the hydroxide $\left(\mathrm{OH}^{-}\right)$group [22].

The obtained hierarchical $\mathrm{Ag} @ \mathrm{Ni}(\mathrm{OH})_{2}$ nanospheres sample on copper substrate was directly used as binder-free electrodes for the electrochemical performance estimation in a three-electrode system. Figure 5a displays the CV curves of different electrodes at the scan rate of $5 \mathrm{mV} \mathrm{s}^{-1}$ at potential window of 0-0.6 V, including $\mathrm{Ag} @ \mathrm{Ni}(\mathrm{OH})_{2}$ (immerse copper substrate in $0.01 \mathrm{M}$ of $\mathrm{AgNO}_{3}$ solution for $10 \mathrm{~min}$ and then electrodeposition of $300 \mathrm{~s}$ on the obtained Ag electrode surface using $0.05 \mathrm{M}$ of $\mathrm{Ni}\left(\mathrm{NO}_{3}\right)_{2} \cdot 6 \mathrm{H}_{2} \mathrm{O}$ as electrolyte), $\mathrm{Ni}(\mathrm{OH})_{2}$ (electrodeposition of $300 \mathrm{~s}$ on copper substrates using $0.05 \mathrm{M}$ of $\mathrm{Ni}\left(\mathrm{NO}_{3}\right)_{2} \cdot 6 \mathrm{H}_{2} \mathrm{O}$ as electrolyte), Ag electrode (immerse copper substrate in $0.01 \mathrm{M}$ of $\mathrm{AgNO}_{3}$ solution for $10 \mathrm{~min}$ ) and copper foam substrate. As can be seen, the CV curve integral area of the 
$\mathrm{Ag} @ \mathrm{Ni}(\mathrm{OH})_{2}$ electrode is much larger than those of the others, demonstrating the highest specific capacity of the Ag@Ni(OH $)_{2}$ composite electrode. The $\mathrm{Ag} @ \mathrm{Ni}(\mathrm{OH})_{2}$ electrode shows two pairs of redox peaks in the voltammogram where the sharp and strong peaks at $0.5 \mathrm{~V}$ and $0.3 \mathrm{~V}$ are ascribed to the redox couple $\mathrm{Ni}^{2+} / \mathrm{Ni}^{3+}$, and the broad and small peaks at $0.27 \mathrm{~V}$ and $0.10 \mathrm{~V}$ are ascribed to the redox couple $\mathrm{Ag} / \mathrm{Ag}^{+}$as below [23]:

$$
\begin{gathered}
\mathrm{Ni}(\mathrm{OH})_{2}+\mathrm{OH}^{-} \leftrightarrow \mathrm{NiOOH}+\mathrm{H}_{2} \mathrm{O}+\mathrm{e}^{-} \\
2 \mathrm{Ag}+2 \mathrm{OH}^{-} \leftrightarrow \mathrm{Ag}_{2} \mathrm{O}+\mathrm{H}_{2} \mathrm{O}+2 \mathrm{e}^{-}
\end{gathered}
$$

Figure $5 \mathrm{~b}$ reveals the GCD curves of the $\mathrm{Ag} @ \mathrm{Ni}(\mathrm{OH})_{2}, \mathrm{Ni}(\mathrm{OH})_{2}$ and $\mathrm{Ag}$ electrode at $2 \mathrm{~mA} \mathrm{~cm}{ }^{-2}$, where $\mathrm{Ag} @ \mathrm{Ni}(\mathrm{OH})_{2}$ electrode presents the longest discharge time, consistent with the $\mathrm{CV}$ measurements. It can be noticed that the intensity of redox peaks of $\mathrm{Ag}$ becomes weaker and weaker with the continuous deposition of $\mathrm{Ni}(\mathrm{OH})_{2}$ layer (Supplementary Materials Figure S1a). The corresponding GCD curves in Figure S1b illustrate a tiny plateau at about $0.15 \mathrm{~V}$, corresponding to the redox couple $\mathrm{Ag} / \mathrm{Ag}^{+}$[24-26]. As can be observed, the plateau period becomes shorter with the continuous deposition of $\mathrm{Ni}(\mathrm{OH})_{2}$.
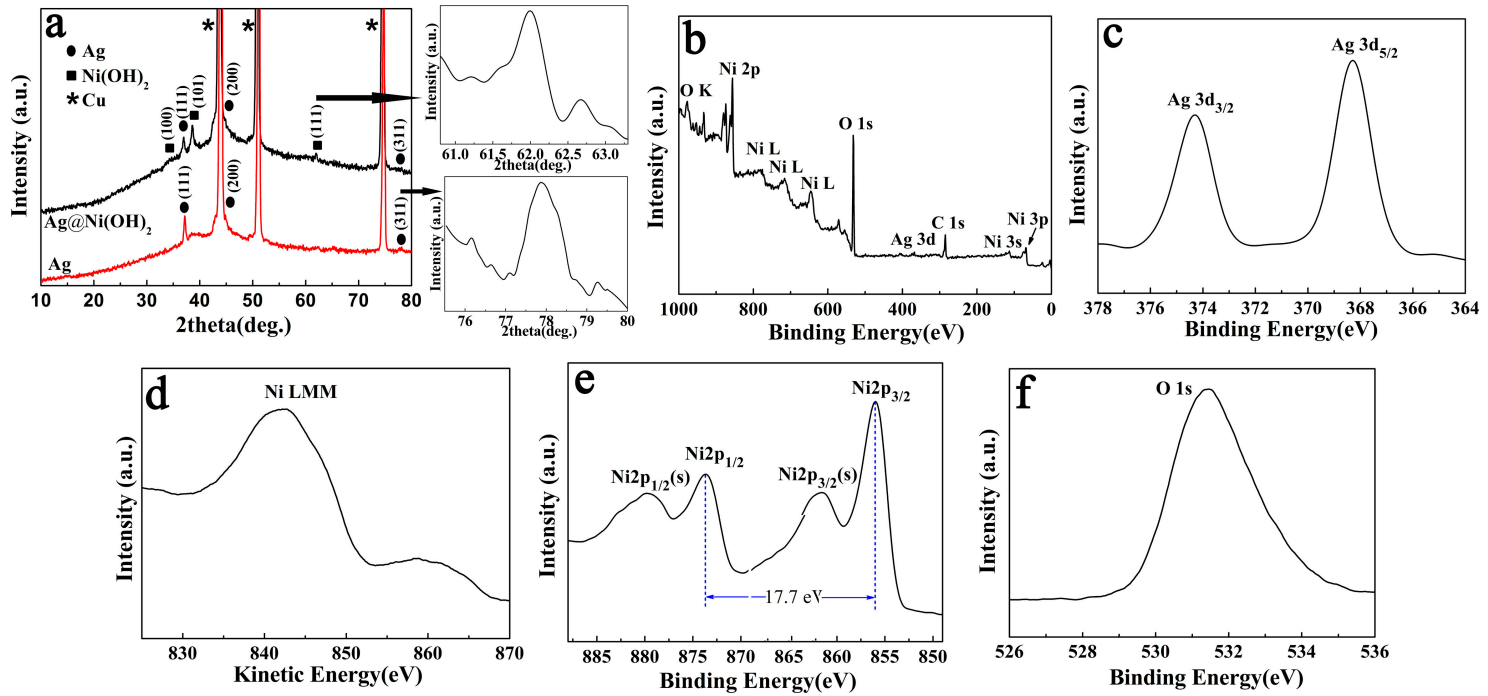

Figure 4. (a) XRD patterns of $\mathrm{Ag}$ and $\mathrm{Ag} @ \mathrm{Ni}(\mathrm{OH})_{2}$ (The arrows point to a higher magnification); $(\mathbf{b}-\mathbf{f})$ XPS spectra of the Ag@Ni(OH) $)_{2}$ : survey scan, Ag 3d, Ni LMM, Ni 2p and O 1s.
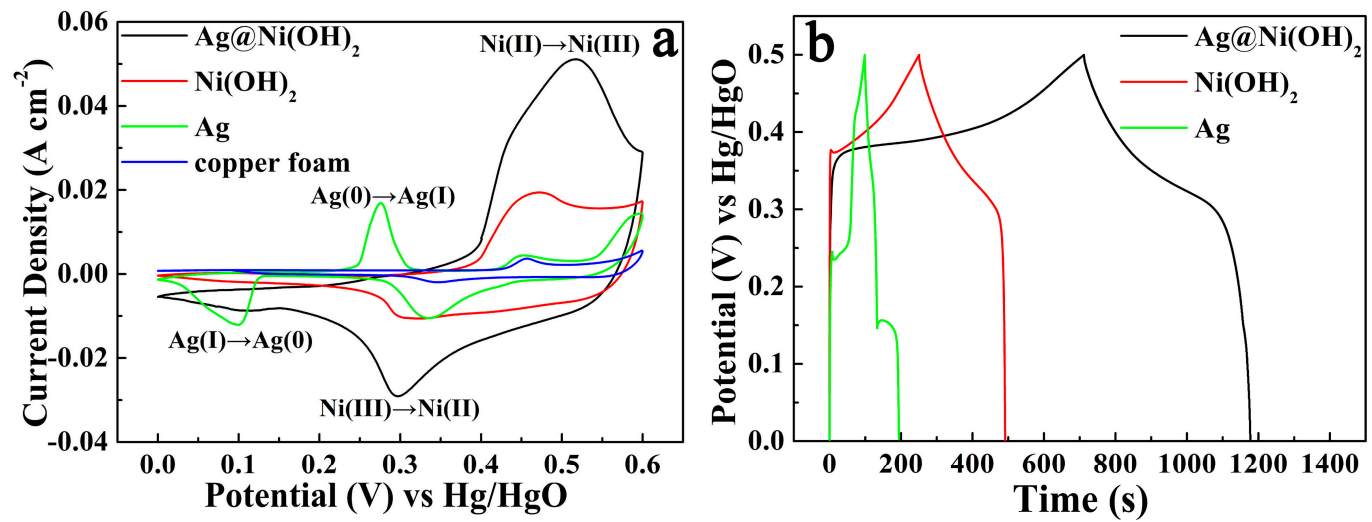

Figure 5. (a) CV curves of $\mathrm{Ag} @ \mathrm{Ni}(\mathrm{OH})_{2}, \mathrm{Ni}(\mathrm{OH})_{2}$ and $\mathrm{Ag}$ as electrodes, and copper foam substrate at a scan rate of $5 \mathrm{mV} \mathrm{s}^{-1} ;(\mathbf{b})$ a comparison of GCD curves of the three electrodes. 
The $\mathrm{CV}$ curves of the $\mathrm{Ag} @ \mathrm{Ni}(\mathrm{OH})_{2}$ electrode were recorded at various scan rates ranged from 2 to $50 \mathrm{mV} \mathrm{s}^{-1}$ within the potential range of $0-0.6 \mathrm{~V}$, as seen from Figure $6 \mathrm{a}$. A pair of strong redox peaks with good symmetry are observed, and all the CV curves maintain similar shape. The current response increases with scan rate, that is, the oxidation and reduction peak potentials move to more positive and negative directions, respectively, on the contrary, the specific capacitance decreases with the increase of scan rate according to the equation in Supplementary Materials. The decrease may be attributed to the fact that many internal electroactive sites of the electrode are inadequate participated in redox reactions at high scan rates due to the limitation of ionic/electronic diffusion [27]. The typical GCD tests were further performed in a potential window of $0-0.5 \mathrm{~V}$ at different current densities ranged from 2 to $20 \mathrm{~mA} \mathrm{~cm}^{-2}$ (Figure $6 \mathrm{~b}$ ). The symmetric and nonlinear profile of the GCD curves exhibits good pseudo-capacitance characteristics. The specific capacitance of $\mathrm{Ag} @ \mathrm{Ni}(\mathrm{OH})_{2}$ electrode can be obtained by the equation in Supplementary Materials [28]. In addition, the CV and GCD measurements of $\mathrm{Ni}(\mathrm{OH})_{2}$ and $\mathrm{Ag}$ electrode were also performed for comparison in Figure S2. Figure 6c shows the comparative plots of the specific capacitance versus current density of $\operatorname{Ag} @ N i(O H)_{2}$, $\mathrm{Ni}(\mathrm{OH})_{2}$ and $\mathrm{Ag}$ electrodes. The specific capacitance values of the three electrodes are shown in Table S1 in Supplementary Materials. The specific capacitance of $\mathrm{Ag} @ \mathrm{Ni}(\mathrm{OH})_{2}$ decreases from 1.864 to $0.760 \mathrm{~F} \mathrm{~cm}^{-2}$, corresponding to the discharge current density from 2 to $20 \mathrm{~mA} \mathrm{~cm}^{-2}$, respectively, which are much higher than $\mathrm{Ni}(\mathrm{OH})_{2}$ and $\mathrm{Ag}$ electrodes. Meanwhile, the average equivalent series resistance $\left(R_{\mathrm{ESR}}\right)$ is $0.988 \Omega \mathrm{cm}^{-2}$, the equation and data (Table S2) are displayed in Supplementary Materials [8] (Figure 6d). The low $R_{\mathrm{ESR}}$ is attributed to the direct growth of Ag on copper foam substrate using galvanic replacement reaction that leads to strong interaction between them. Meanwhile, the Ag nanostructures with good conductivity act as both collector and effective constituent of the active material.
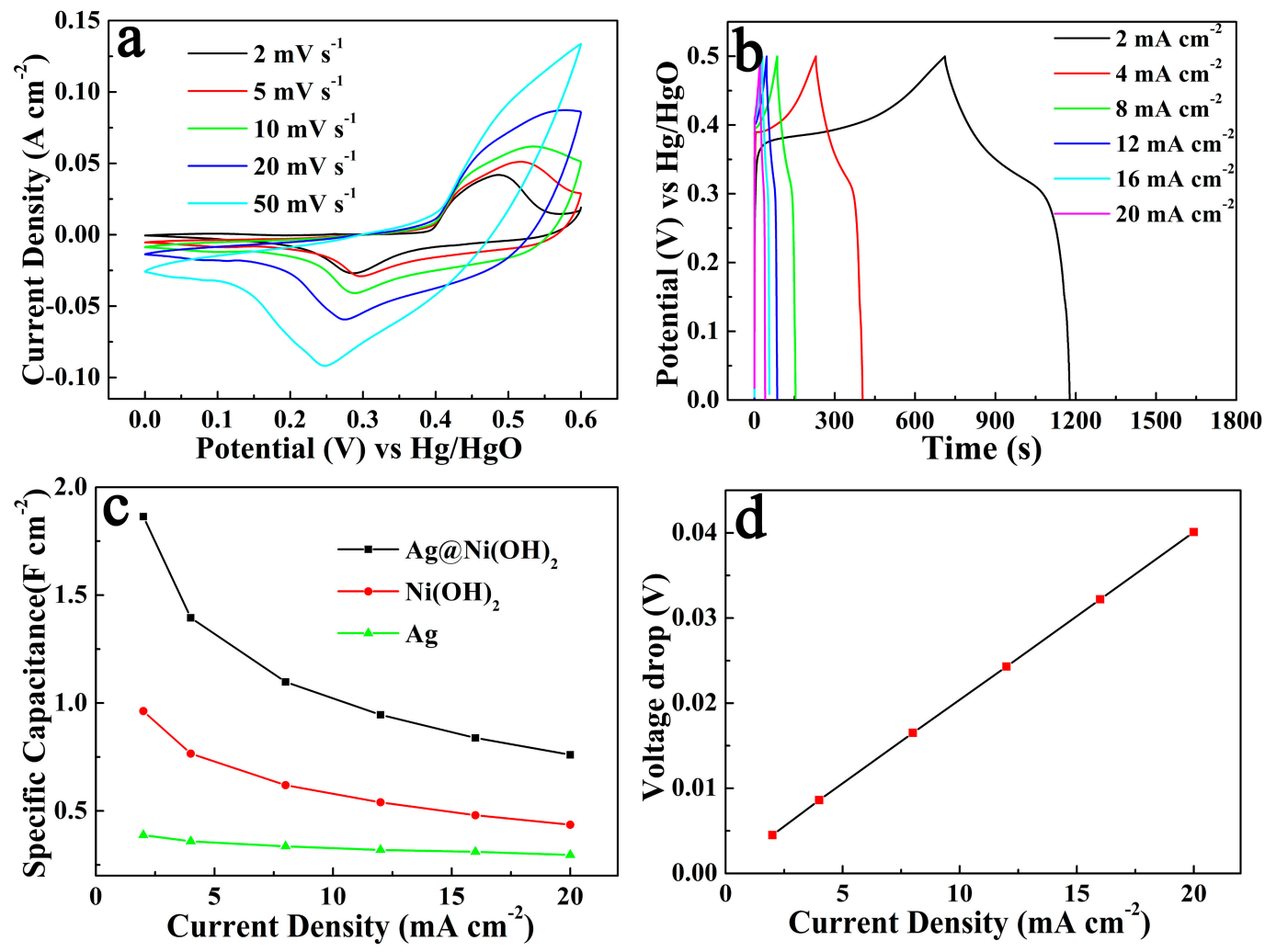

Figure 6. (a) The CV curves, (b) GCD curves, (c) plots of specific capacitance versus current density and $(\mathbf{d})$ voltage drops during the GCD tests of the $\mathrm{Ag} @ \mathrm{Ni}(\mathrm{OH})_{2}$ electrode.

Figure 7 shows the specific capacitance retention curve of the $\mathrm{Ag} @ \mathrm{Ni}(\mathrm{OH})_{2}$ electrode. It maintains $90.43 \%$ of its original specific capacitance value and no obvious structure deformation (Figure S3) after 
3000 cycles. This good cyclic property is attributed to the effective bonding between active materials and copper substrate.

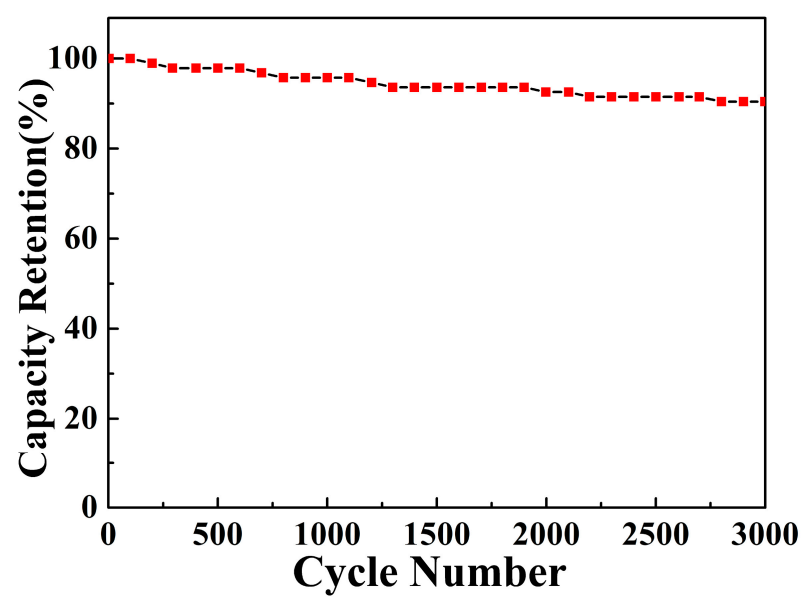

Figure 7. Cycling performances of the $\mathrm{Ag} @ \mathrm{Ni}(\mathrm{OH})_{2}$ electrode.

The resulting hierarchical Ag@Ni(OH $)_{2}$ samples available in high performance binder-free electrodes may be mainly attributed to the following factors: (1) the Ag nanoflowers directly grown on copper substrate by the electroless deposition techniques reduces the contact resistance, and provides a natural pathway for electron transport thereby [22]; (2) The use of Ag nanoflowers as backbone provides adequate surface area for subsequent $\mathrm{Ni}(\mathrm{OH})_{2}$ layer deposition and allows fast electric and ionic conduction through the electrode owing to its good electrical conductivity [27]; (3) The electrodeposition of $\mathrm{Ni}(\mathrm{OH})_{2}$ nanospheres are composed by smaller nanoparticles, which interconnect with each other on the surface of the Ag nanoflowers and this generates abundant space, enabling the electrolyte to fully infiltrated into the internal area of the electrode, and thus ensuring full utilization of active electrode materials [29].

\section{Conclusions}

In summary, hierarchical $\mathrm{Ag} @ \mathrm{Ni}(\mathrm{OH})_{2}$ nanospheres have been designed and in-situ constructed on copper foam substrate through the combination of electroless deposition technology with electrodeposition. Copper foam acts as both reducing agent and substrate. The resulting $\operatorname{Ag@Ni(OH})_{2}$ samples could be directly used as high performance binder-free electrodes and exhibited a high specific capacitance value of $1.864 \mathrm{~F} \mathrm{~cm}^{-2}$, low $R_{\mathrm{ESR}}$ of $0.988 \Omega \mathrm{cm}^{-2}$, and good cycling stability with a capacitance retention of $90.43 \%$ after 3000 cycles. The good electrochemical properties should be ascribed to the synthesis strategy and the effective utilization of Ag as backbone, which can increase the electrical conductivity and the specific surface area of the active material. Moreover, this convenient method can be extended to construct other binary or multiple composites with Ag as conductive reinforcement.

Supplementary Materials: The following are available online at http:/ /www.mdpi.com/2073-4352/9/2/118/s1, Figure S1: Ag@Ni(OH) $)_{2}$ electrode corresponding to different $\mathrm{Ni}(\mathrm{OH})_{2}$ deposition time: (a) CV curves; (b) GCD curves. Figure S2: $(\mathrm{a}, \mathrm{c})$ The CV curves and $(\mathrm{b}, \mathrm{d}) \mathrm{GCD}$ curves of $\mathrm{Ni}(\mathrm{OH})_{2}$ and the Ag electrode, respectively. Figure S3. FE-SEM images of the $\mathrm{Ag} @ \mathrm{Ni}(\mathrm{OH})_{2}$ composite at different magnifications after 3000 cycles. Table $\mathrm{S} 1$. The specific capacitance versus current density of the three electrodes. Table S2. The $\mathrm{R}_{\mathrm{ESR}}$ and voltage drop versus current density of the $\mathrm{Ag} @ \mathrm{Ni}(\mathrm{OH})_{2}$ electrode. Equations for calculating specific capacitance and average equivalent series resistance.

Author Contributions: Formal analysis, Y.C.; Investigation, S.L.; Methodology, X.C. and F.Y.; Software, J.Y.; Supervision, H.W. and X.Y.; Writing-original draft, S.L.; Writing-review\&editing, X.Y.

Funding: This research was funded by The National Key Technology R\&D Program of China (Grant No. 2016YFB0401103) and National Natural Science Foundation of China (Grant No. 51672103). 
Conflicts of Interest: The authors declare no conflicts of interest.

\section{References}

1. Saha, S.; Samanta, P.; Murmu, N.C.; Kuila, T. A review on the heterostructure nanomaterials for supercapacitor application. J. Energy Storage 2018, 17, 181-202. [CrossRef]

2. Guo, J.X.; Zhang, X.Q.; Sun, Y.F.; Zhang, X.H.; Tang, L.; Zhang, X. Double-shell CuS nanocages as advanced supercapacitor electrode materials. J. Power Sources 2017, 355, 31-35. [CrossRef]

3. Dai, X.; Chen, D.; Fan, H.Q.; Zhong, Y.; Chang, L.; Shao, H.B.; Wang, J.M.; Zhang, J.Q.; Cao, C.N. $\mathrm{Ni}(\mathrm{OH})_{2} / \mathrm{NiO} / \mathrm{Ni}$ composite nanotube arrays for high-performance supercapacitors. Electrochim. Acta 2015, 154, 128-135. [CrossRef]

4. Liu, G.L.; Zhao, C.; Liu, T.Y.; He, D.; Suo, H. Facile route to achieve book-like tricobalt tetraoxide microstructures on copper foam for high performance supercapacitor. Mater. Lett. 2018, 220, 78-81. [CrossRef]

5. Gao, L.; Zhang, L.L.; Jia, S.Y.; Liu, X.C.; Wang, Y.H.; Xing, S.X. Facile route to achieve hierarchical hollow $\mathrm{MnO}_{2}$ nanostructures. Electrochim. Acta 2016, 203, 59-65. [CrossRef]

6. Wang, T.; Pan, J.Q.; Achille, G.K.; Sun, Y.Z. A green dual complexation precipitation synthesis of hierarchical $\alpha-\mathrm{Ni}(\mathrm{OH})_{2}$ microspheres and their electrochemical performance. Int. J. Hydrogen Energy 2017, 42, 19139-19147. [CrossRef]

7. Wiston, B.R.; Ashok, M. Electrochemical performance of nickel hydroxide nanopetals for supercapacitor electrodes. Mater. Lett. 2019, 235, 76-79. [CrossRef]

8. He, D.; Wang, G.D.; Liu, G.L.; Suo, H.; Zhao, C. Construction of leaf-like CuO-Cu $2 \mathrm{O}$ nanocomposite on copper foam for high-performance supercapacitors. Dalton Trans. 2017, 46, 3318-3324. [CrossRef] [PubMed]

9. Khatavkar, S.N.; Sartale, S.D. $\alpha-\mathrm{Fe}_{2} \mathrm{O}_{3}$ thin film on stainless steel mesh: A flexible electrode for supercapacitor. Mater. Chem. Phys. 2019, 225, 284-291. [CrossRef]

10. Lu, H.C.; Chen, J.Z.; Tian, Q.H. Wearable high-performance supercapacitors based on Ni-coated cotton textile with low-crystalline Ni-Al layered double hydroxide nanoparticles. J. Colloid Interface Sci. 2018, 513, 342-348. [CrossRef] [PubMed]

11. Yao, L.Q.; Cheng, T.; Shen, X.Q.; Zhang, Y.Z.; Lai, W.Y.; Huang, W. Paper-based all-solid-state flexible asymmetric micro-supercapacitors fabricated by a simple pencil drawing methodology. Chin. Chem. Lett. 2018, 29, 587-591. [CrossRef]

12. Shi, D.; Zhang, L.; Yin, X.; Huang, T.; Gong, H. One step processed advanced interwoven architecture of $\mathrm{Ni}(\mathrm{OH})_{2}$ and $\mathrm{Cu}$ nanosheets with ultrahigh supercapacitor performance. J. Mater. Chem. A 2016, 4, 12144-12151. [CrossRef]

13. Jeyasubramanian, K.; Gokul Raja, T.S.; Purushothaman, S.; Kumar, M.V.; Sushmitha, I. Supercapacitive performances of $\mathrm{MnO}_{2}$ nanostructures grown on hierarchical $\mathrm{Cu}$ nano leaves via electrodeposition. Electrochim. Acta 2017, 227, 401-409. [CrossRef]

14. Pawar, S.A.; Patil, D.S.; Shin, J.C. Hexagonal sheets of $\mathrm{Co}_{3} \mathrm{O}_{4}$ and $\mathrm{Co}_{3} \mathrm{O}_{4}-\mathrm{Ag}$ for high-performance electrochemical supercapacitors. J. Ind. Eng. Chem. 2017, 54, 162-173. [CrossRef]

15. Zhang, L.Y.; Shi, D.W.; Huang, T.J.; Huang, R.Z.; Gong, H. Light enhanced energy storage ability through hybrid plasmonic Ag nanowires decorated hydroxide "skin structure". Nanoscale 2017, 9, 18430-18437. [CrossRef] [PubMed]

16. Yuksel, R.; Coskun, S.; Kalay, Y.E.; Unalan, H.E. Flexible, silver nanowire network nickel hydroxide core-shell electrodes for supercapacitors. J. Power Sources 2016, 328, 167-173. [CrossRef]

17. Du, H.J.; Pan, Y.; Zhang, X.; Cao, F.Y.; Wan, T.; Du, H.W.; Joshi, R.; Chu, D.W. Silver nanowire/nickel hydroxide nanosheet composite for a transparent electrode and all-solid-state supercapacitor. Nanoscale Adv. 2019, 1, 140-146. [CrossRef]

18. Wu, G.X.; Yang, S.J.; Liu, Q.M. Synthesis of silver nanostructures by simple redox under electrodeposited copper microcubes and the orient attachment growth of 2D silver. Appl. Surf. Sci. 2015, 357, 583-592. [CrossRef]

19. Lo, I.H.; Wang, J.Y.; Huang, K.Y.; Huang, J.H.; Kang, W.P. Synthesis of $\mathrm{Ni}(\mathrm{OH})_{2}$ nanoflakes on ZnO nanowires by pulse electrodeposition for high-performance supercapacitors. J. Power Sources 2016, 308, 29-36. [CrossRef] 
20. Biesinger, M.C.; Lau, L.M.; Gerson, A.R.; Smart, R.C. The role of the Auger parameter in XPS studies of nickel metal, halides and oxides. Phys. Chem. Chem. Phys. 2012, 14, 2434-2442. [CrossRef] [PubMed]

21. Gou, J.X.; Xie, S.L.; Liu, C.G. Flower-like Ni-Co hydroxides on Ni foam for high-performance supercapacitor applications. New J. Chem. 2018, 42, 4175-4181. [CrossRef]

22. Sekhar, S.C.; Nagaraju, G.; Yu, J.S. Conductive silver nanowires-fenced carbon cloth fibers-supported layered double hydroxide nanosheets as a flexible and binder-free electrode for high-performance asymmetric supercapacitors. Nano Energy 2017, 36, 58-67. [CrossRef]

23. Park, S.; Ming Tan, A.W.; Wang, J.X.; Lee, P.S. Coaxial Ag-base metal nanowire networks with high electrochemical stability for transparent and stretchable asymmetric supercapacitors. Nanoscale Horiz. 2017, 2, 199-204. [CrossRef]

24. Cao, F.H.; Wang, Z.H.; Wang, Y.Z.; Yan, Y.M.; Liu, M.T.; Li, L.; Ao, G.H.; Chen, K.F.; Lv, Z. In situ fabrication of cellular architecture on silver metals using methane/oxygen gas mixture and its application for energy storage. Electrochim. Acta 2018, 280, 25-32. [CrossRef]

25. Liu, P.P.; Liu, J.; Cheng, S.; Cai, W.Z.; Yu, F.Y.; Zhang, Y.P.; Wu, P.; Liu, M.L. A high-performance electrode for supercapacitors: Silver nanoparticles grown on a porous perovskite-type material $\mathrm{La}_{0.7} \mathrm{Sr}_{0.3} \mathrm{CoO}_{3-\delta}$ substrate. Chem. Eng. J. 2017, 328, 1-10. [CrossRef]

26. Usman, M.; Pan, L.J.; Sohail, A.; Mahmood, Z.; Cui, R.X. Fabrication of 3D vertically aligned silver nanoplates on nickel foam-graphene substrate by a novel electrodeposition with sonication for efficient supercapacitors. Chem. Eng. J. 2017, 311, 359-366. [CrossRef]

27. Shakir, I.; Ali, Z.; Bae, J.; Park, J.; Kang, D.J. Conformal coating of ultrathin $\mathrm{Ni}(\mathrm{OH})_{2}$ on ZnO nanowires grown on textile fiber for efficient flexible energy storage devices. RSC Adv. 2014, 4, 6324-6329. [CrossRef]

28. Jia, X.-X.; Wu, X.; Liu, B.-D. Formation of $\mathrm{ZnCo}_{2} \mathrm{O}_{4} @ \mathrm{MnO}_{2}$ core-shell electrode materials for hybrid supercapacitor. Dalton Trans. 2018, 47, 15506-15511. [CrossRef] [PubMed]

29. Xing, Z.C.; Chu, Q.X.; Ren, X.B.; Ge, C.J.; Qusti, A.H.; Asiri, A.M.; Al-Youb, A.O.; Sun, X.P. $\mathrm{Ni}_{3} \mathrm{~S}_{2}$ coated ZnO array for high-performance supercapacitors. J. Power Sources 2014, 245, 463-467. [CrossRef]

(C) 2019 by the authors. Licensee MDPI, Basel, Switzerland. This article is an open access article distributed under the terms and conditions of the Creative Commons Attribution (CC BY) license (http:/ / creativecommons.org/licenses/by/4.0/). 